\title{
Xpey' Relational Environments: an analytic framework for conceptualizing Indigenous health equity
}

\author{
Alexandra Kent, MPH (1,2); Charlotte Loppie, PhD (1); Jeannine Carriere, PhD (1); \\ Marjorie MacDonald, PhD, RN (1,2,3); Bernie Pauly, PhD, RN (1,2,3)
}

This article has been peer reviewed.

Tweet this article

\begin{abstract}
Introduction: Both health equity research and Indigenous health research are driven by the goal of promoting equitable health outcomes among marginalized and underserved populations. However, the two fields often operate independently, without collaboration. As a result, Indigenous populations are underrepresented in health equity research relative to the disproportionate burden of health inequities they experience. In this methodological article, we present Xpey' Relational Environments, an analytic framework that maps some of the barriers and facilitators to health equity for Indigenous peoples.
\end{abstract}

Methods: Health equity research needs to include a focus on Indigenous populations and Indigenized methodologies, a shift that could fill gaps in knowledge with the potential to contribute to 'closing the gap' in Indigenous health. With this in mind, the Equity Lens in Public Health (ELPH) research program adopted the Xpey' Relational Environments framework to add a focus on Indigenous populations to our research on the prioritization and implementation of health equity. The analytic framework introduced an Indigenized health equity lens to our methodology, which facilitated the identification of social, structural and systemic determinants of Indigenous health. To test the framework, we conducted a pilot case study of one of British Columbia's regional health authorities, which included a review of core policies and plans as well as interviews and focus groups with frontline staff, managers and senior executives.

Conclusion: ELPH's application of Xpey' Relational Environments serves as an example of the analytic framework's utility for exploring and conceptualizing Indigenous health equity in BC's public health system. Future applications of the framework should be embedded in Indigenous research methodologies.

Keywords: health equity, health services accessibility, public health, research methodology, Indigenous populations

\section{Introduction}

Within Canada and abroad, two emerging branches of health research are rapidly advancing and have the potential to inform each other: health equity research and Indigenous health research. Health equity research is the investigation of disparities in health status or the delivery of health care; ${ }^{1}$ it is also the study of strategies, programs or policies to reduce/ eliminate inequities and promote health equity. Indigenous health research is the study of the health and well-being of Indigenous populations, which often entails the application of Indigenized or decolonizing research methods that infuse Indigenous ways of knowing and cultural protocols into research practice. ${ }^{2,3}$

Both branches of research are driven by the goal of promoting equitable health outcomes among marginalized and underserved populations; however, the two fields tend to operate independently, often
Highlights

- Indigenous peoples in Canada face inequities in access to health services as well as health outcomes, which are unnecessary and unjust.

- There are various determinants of Indigenous health, including protective features that promote wellbeing and resilience, as well as risk factors that can produce unfavorable circumstances or hinder health.

- Indigenous health equity is a critical issue in BC's public health system and needs to be a priority for researchers, policy makers and practitioners.

- Making Indigenous populations a priority in public health policy, practice and research can contribute to improving the overall health and wellness of Indigenous peoples.

without collaboration. $^{2}$ This disconnect may have an impact on how Indigenous health equity is investigated, if at all. ${ }^{1}$ Health equity research needs to include a focus on Indigenous populations and Indigenized methodologies. This shift could fill this gap in knowledge with the potential to contribute to 'closing the gap' in Indigenous health.

In this article, we present Xpey' Relational Environments, an analytic framework designed for conceptualizing the physical, interpersonal and institutional settings where Indigenous health equity may or may not be manifest. We showcase the framework's application within the Equity Lens in Public Health (ELPH) research 
program as an example of its relevance to analyzing Indigenous health equity within public health environments. Xpey' Relational Environments has been used by the ELPH research team to explore strategies used by British Columbia's (BC's) public health system to reduce inequities and enhance health equity for Indigenous peoples, including First Nations, Inuit and Métis peoples. The specific research questions that ELPH seeks to answer are: (1) What are the barriers and facilitators to health equity within BC's public health system? (2) What specific strategies are proposed and implemented by health authorities to address health equity? (3) To what extent has health equity been identified and prioritized within health authorities as reflected in core documents and plans? and (4) What are the contextual influences on priority setting and equity goals at the organizational and broader systems levels? Xpey' Relational Environments adds a specific focus on Indigenous peoples in answer to these questions and an Indigenous lens to the analysis of the data.

\section{Locating ourselves in this research}

\section{Alexandra Kent}

I locate myself in this research as a fifthgeneration Canadian settler of British and Dutch ancestry. Though I do not care to label myself as such, I am positioned in society as a white, Western-educated, English-speaking, able-bodied, heterosexual woman. I acknowledge that by embodying this intersectional identity, I am privileged as a member of several dominant groups. Furthermore, as a settler living on the unceded territories of Songhees, Esquimalt and WSÁNEĆ peoples, I am implicated in Canada's history of colonialism as a beneficiary of the dispossession and subjugation of Indigenous peoples. I am approaching this research with humility and the understanding that I do not represent Indigenous peoples or their knowledge, worldviews, and cultural lenses. I hope to contribute to the decolonization agenda as a non-Indigenous ally through critical engagement with public health research. I have had the privilege of working as a Research Fellow, and more recently a Research Assistant, with the Equity Lens in Public Health (ELPH) research program and the Centre for Indigenous Research and Community-Led Engagement (CIRCLE), who partnered to add an Indigenous focus and Indigenous knowledge to the ELPH project. Working with both ELPH and CIRCLE has given me a unique perspective that integrates Western academia with Indigenous ways of knowing, much like Two-Eyed Seeing. ${ }^{4}$ It is from this position and with critical awareness of my location that I present Xpey' Relational Environments with my colleagues.

\section{Charlotte Loppie}

I am of Mi'kmaq and French Acadian ancestry from Nova Scotia. I have been a grateful visitor in the territory of the Songhees, Esquimalt and WSÁNEĆ peoples since 2009. I have served the health research needs of Indigenous communities and collectivities since 1995; I teach Indigenous health courses in the School of Public Health and Social Policy at the University of Victoria, where I also serve as the Director of the Centre for Indigenous Research and Community-Led Engagement (CIRCLE). I am not an Investigator on the ELPH project but was asked by the team to co-develop the Xpey' Relational Environments framework, which I hope will support Indigenous health equity in BC and elsewhere.

\section{Jeannine Carriere}

My Cree name is Sohki Aski Esquao, which means Strong Earth Woman. My English name is Jeannine Carriere. I am a Métis woman who comes from the Red River area of Manitoba and I have been living in the territory of the Cowichan peoples on Vancouver Island since 2005. I have been teaching since 1994 and at the University of Victoria on the territory of the Songhees, Esquimalt and WSÁNEĆ peoples in the School of Social Work since 2005. My areas of research include adoption and identity for Indigenous children, Indigenous research methodologies, Metis child and family wellbeing and family relationships in sex work. Through these areas of interest I have been fortunate to publish and develop networks with some amazing folks such as those affiliated with the ELPH project. For this, I am grateful.

\section{Marjorie MacDonald}

I am positioned in this research as a welleducated, white, able-bodied, middleclass heterosexual woman. This has provided me with privileges not open to many others in society. Although my great-grandmother on my mother's side was Cree, her descendents were all raised as white settlers, sadly without knowledge about or acknowledgement of their Cree heritage. Thus, we are all implicated in the colonization and oppression of Indigenous peoples in this country, including our own relatives. I lived and worked on the Blackfoot Reserve at Gleichen Alberta and came to learn and appreciate the traditions and worldview of the Blackfoot. This experience led me to make a life-long commitment to public health with its communitarian values and collectivist ethic. Yet, I claim no special knowledge, position, or privilege in this research related to this experience. As a committed ally, I acknowledge, with gratitude and humility, my visitor status in the unceded territories of the Songhees, Esquimalt and WSÁNEĆ peoples.

\section{Bernadette Pauly}

I am a third generation settler of German ancestry. I am positioned in society as a white, able bodied, well-educated heterosexual middle class woman. I have had opportunities and privileges open to me as a result of my position in society. I am a settler living and working on the unceded territories of the Songhees, Esquimalt and WSÁNEĆ peoples since 2000. As such, I am implicated in the colonial history of Canada and actions of many Canadian settlers that resulted in the displacement and oppression of Canada's Indigenous peoples. In this research, I recognize that my position is not one of belonging to or intimate knowledge of Indigenous knowledge, worldviews, or cultural lenses. My aim is to approach this research respectfully and humbly in the hopes that critical engagement will contribute to the decolonization agenda. I am extremely grateful and appreciative of the opportunity to work with Indigenous scholars in this work and in other research, and have learnt an enormous amount through these processes. For that, I am thankful.

\section{Equity Lens in Public Health research program}

ELPH is a five-year program of research funded by CIHR in 2011 that grew out of the Core Public Health Functions Research Initiative (CPHFRI), which was initiated in 2005. Both CPHFRI and ELPH are specific to BC's public health system, and operate in close partnership with BC's five regional health authorities, the Ministry of Health, and the Provincial Health Services Authority (PHSA), among other partners. These partnerships were solidified prior to ELPH's inception in 2011. The First Nations 
Health Authority (FNHA) was invited to partner with ELPH in 2013 (when it was formally established); we respect their decision to not participate and take this into consideration as a limitation of the study.

The ELPH research program is dedicated to the development and application of an equity lens in public health and the implications for reducing health inequities. ${ }^{5}$ It has a particular focus on mental health promotion and preventing mental illness and the harms of substance use. The project is organized into four distinct but interrelated studies. Xpey' Relational Environments was used in a case study within ELPH Study 1: Health Equity Priorities and Strategies, the intent of which is to conduct individual case studies among BC's five regional health authorities to determine: (1) current activity on health equity and inequity reduction; (2) whether and how health equity issues have been prioritized; (3) the contextual influences on priorities and health equity plans/strategies; and (4) how and what explains these changes over the course of the study. Each health authority represents an individual case to capture contextual influences at the regional level and facilitate comparison across cases. The case study design also enables comparative analysis across times (baseline and follow-up) for assessment of changes in the uptake and implementation of health equity as a priority.

The ELPH project uses situational analysis, which is an approach to research using post-modern grounded theorizing methodology to identify and describe social worlds and arenas of action to understand the human and non-human elements, interactions and context within a specified situation. ${ }^{6}$ Consistent with Clarke's ${ }^{6}$ methodology, we are using situational analysis to open up the data and to facilitate analysis of multiple connections and relationships that can influence activities. Ordered, relational, social world, and positional maps are visual representations for understanding the phenomena of interest and the complexity inherent in a situation. As an outcome of the ELPH study, we will produce regional case reports and an overall provincial level analysis that summarizes findings related to application and implementation of health equity across health authorities. ${ }^{5}$ The situational analysis will be reported elsewhere.

\section{Background}

In the original ELPH proposal, health inequities among Indigenous peoples, including First Nations, Inuit and Métis peoples, were highlighted as a concern in $\mathrm{BC}$ along with health inequities of other sub-populations. The ELPH team identified the need to pay special attention to health equity for Indigenous peoples, which would require a more culturally relevant analytic framework. Consequently, the Principal Investigators approached Indigenous researchers, Dr. Charlotte Loppie (CL, formerly Reading) and Dr. Jeannine Carriere (JC), who developed the Xpey' Relational Environments framework which serves as the basis of a parallel analysis that uses an Indigenous lens to explore the role of public health in Indigenous health equity.

\section{The Haudenosaunee Gusweñta model (or Two Row Wampum)}

The ELPH team acknowledges the Haudenosaunee Gusweñta, or Two Row Wampum, as a model for conceptualizing the relationship between ELPH's use of situational analysis methodology and the Xpey' Relational Environments approach. The Gusweñta, or Two Row Wampum, is a beaded belt that was exchanged at the Treaty of Niagara in 1764 . The belt depicts two boats (a First Nations canoe and a European ship) traveling side by side down a river, neither of them trying to steer the other's vessel or intersect the other's path, symbolizing mutual respect and non-interference. ${ }^{7}$ Like the Two Row Wampum, our analysis represents parallel processes that share an overarching purpose and a common data set. Our research recognizes Indigenous and Western approaches as distinctly yet equally significant, and draws together the strengths of both to allow for a "wider, deeper, and more generative 'field of view' than might either of these perspectives [provide] in permanent isolation". ${ }^{4}$ Furthermore, we take caution not to merge the two knowledge systems into one or try to force Indigenous knowledge into a Western paradigm.

\section{State of knowledge}

ELPH's research is grounded in a body of literature on health equity and public health systems. Although knowledge and awareness are expanding in these areas, relatively little research has bridged the two or further linked them to Indigenous health. In 2010, the Canadian Coalition for Global Health Research partnered with the Centre for Aboriginal Health Research [what is now CIRCLE] on a project titled, "Linking Equity Methods Research and Global Indigenous Health Research." The project included an environmental scan, tools inventory, and workshop to develop a work plan for forwarding an agenda for collaboration between the two fields of research. ${ }^{2,8}$ The investigators concluded that, "While advancements in equity methods research have been made in the past decade... more work was needed on research evidence focused on the health of Indigenous populations", 8,p.2 The following sections will briefly outline some of the pertinent background information to set the context for our research.

\section{Health equity}

The standard definition of health inequity used in research circles is "differences in health which are not only unnecessary and avoidable but, in addition, are considered unfair and unjust" ${ }^{\text {,p. }}$. On the other hand, the presence of equity can be detected when those who are marginalized in society have access to the highest attainable standard of health, as measured by the health status of the most advantaged. ${ }^{10}$ In BC and elsewhere, Indigenous peoples share a disproportionate burden of inequities. There is no universally recognized formal definition of 'Indigenous' peoples, as each community, nation and collectivity has the right to define and identify itself. Indigenous peoples, communities and nations can be generally understood as those that have "a historical continuity with pre-invasion and precolonial societies that developed on their territories, [and] consider themselves distinct from other sectors of the societies now prevailing on those territories, or parts of them."2

Many researchers have explored the health status of Indigenous populations in Canada and around the world, and further linked this issue to inequities within determinants of health that extend beyond personal behaviour and genetics to encompass broader socio-political factors that influence health in profound ways. ${ }^{11-16}$ There is a recent movement in Indigenous health research away from the pathologizing lens that sensationalizes disparities or 'deficiencies' experienced within Indigenous communities, and realigns the focus toward 
the role of structural injustices in shaping social conditions.

ELPH does not intend to reproduce findings from other studies that highlight inequitable health status, rather, the purpose of this research is to examine the role of public health systems and structures in the perpetuation or interruption of these inequities. Health care systems, including the public health system, have a mandate to provide services that promote, restore, or maintain the population's health. BC's Guiding Framework for Public Health ${ }^{17}$ outlines public health core functions, including: preventing disease, illness and injury; protecting populations from health risks; and promoting healthy public policies, environments and behaviours. Public health has two overarching moral aims: promoting the health of the population and reducing health inequities. ${ }^{18}$ The public health system has therefore been identified as an important site for action to promote health equity as well as ameliorate health inequities. However, as a colonial system, it also has the potential to contribute to increased inequities, particularly in relation to existing barriers to accessing health care for Indigenous peoples.

\section{Historical and institutional background}

Barriers to health equity for Indigenous peoples can often be manifested in the public health system in the form of fragmented governance, jurisdictional complexity, gaps in service coverage, and lack of government accountability. These issues have been noted and problematized in landmark reports, including the Final Report of the Truth and Reconciliation Commission of Canada, ${ }^{16}$ the Final Report of the Royal Commission on Aboriginal Peoples, ${ }^{19}$ and the Report of the Chief Public Health Officer. ${ }^{13}$ Canada's system of Indigenous health governance has been characterized as a "bureaucratic maze" 11,p.5 and "a complex patchwork of policies, legislation and relationships". ${ }^{20, p .1}$ These issues can be traced back to the 1867 British North America (BNA) Act, which stipulates that "Indians and the lands reserved for Indians" are a federal jurisdiction (Section 91[24]) and health care, social services and education, are provincial jurisdictions. ${ }^{21}$

The jurisdictional boundaries outlined by the BNA Act may be clear in theory, but have proven to be ambiguous and convoluted in practice. The divisions not only exist across tiers of government, but also translate to divisions across ancestry, places of residence, and land claim agreements. These jurisdictional divisions create confusion over the provision of health services to Indigenous people, and produce overlapping responsibilities among governing authorities at the federal and provincial/territorial levels. Over the years, Indigenous peoples have sought increased control over decisions relating to health policies, programs and services; however, it is unclear whether this has ameliorated or exacerbated jurisdictional complexity..$^{20,22-24}$

\section{British Columbia's public health system}

The BC Core Public Health Functions Framework ${ }^{25}$ and the subsequent Guiding Framework for Public Health ${ }^{17}$ point out that the core functions of public health are the responsibility of the health system at large, non-governmental and private organizations, and civil society; i.e. public health functions are not solely carried out by the formal public health system and traditional public health practitioners. In the ELPH program of research, however, our focus is on the formal public health system in which the aim of policy and practice is health promotion, disease and injury prevention, health protection, and surveillance and assessment, rather than treatment and cure as it is in the larger health care system.

BC's formal public health system is made up of the Ministry of Health, the Provincial Health Services Authority (PHSA), five regional health authorities (Northern Health, Interior Health, Fraser Health, Vancouver Coastal Health, and Island Health), and First Nations Health Authority (FNHA). ${ }^{26}$ In December 2001, the provincial government merged the previous 52 health authorities into five in an attempt to streamline a complicated and expensive health care system. ${ }^{26}$ The regional health authorities are responsible for planning, managing, and delivering health programs and services within their geographic areas. ${ }^{26}$ The Ministry of Health supports and funds the programs and services of all health authorities and provides guidance to ensure a standardized level of quality across geographic regions and populations. ${ }^{26}$ The Provincial Health Services Authority also works with the regional health authorities and supporting organizations to plan and coordinate provincial programs and specialized health services throughout the province. ${ }^{26}$ These governing authorities work together to provide comprehensive health services to all British Columbians.

FNHA is the newest health authority in $\mathrm{BC}$ that specifically represents and serves First Nations people. It is part of a unique health governance framework among First Nations, the Province of $\mathrm{BC}$, and the Government of Canada that is a first of its kind in Canada. A tripartite framework facilitates the transfer of responsibilities for the planning, design, management and delivery of First Nations health programs and services in BC from Health Canada's First Nations and Inuit Health Branch to FNHA. The transfer officially took place on October $1^{\text {st }}$, 2013, but is the product of extensive consultations and negotiations formalized in a series of three health agreements: the Transformative Change Accord: First Nations Health Plan (2006), the Tripartite First Nations Health Plan (2007), and the BC Tripartite Framework Agreement on First Nation Health Governance (2011). ${ }^{27}$ These three agreements form a legally binding framework that outlines the First Nations health governance structure and mandate, the federal and provincial funding commitments, and the unified vision for an integrated health system.

The creation of FNHA does not add to jurisdictional complexity through separate First Nations and non-First Nations health systems; rather, it promotes stronger linkages between FNHA, Health Canada, the BC Ministry of Health, and BC health authorities. ${ }^{27}$ Ultimately, coordination and collaboration among these partners should improve the quality, accessibility, effectiveness, and efficiency of health programs and services for First Nations by reducing complexity and promoting more integrated service delivery. The new framework also increases First Nations control over health governance, which enhances the acceptability of these services through incorporation of culturally relevant models of wellness. FNHA has a "community-driven, nation-based" mandate that represents the diversity of $\mathrm{BC}$ First Nations peoples and cultures. ${ }^{22}$ However, FNHA's mandate applies exclusively to registered First Nations people, and does not address the needs of other Indigenous groups (e.g. Métis, Inuit, nonstatus) in $\mathrm{BC} .^{20}$ The federal government distinguishes between registered (or status) 
and non-registered (or non-status) Indians. A registered Indian is a person registered under the terms of the Indian Act. ${ }^{20}$ It is anticipated that as time goes on, FNHA will play a greater role in influencing the planning and delivery of services to the wider Indigenous population in BC and potentially the non-Indigenous population as well. ${ }^{27}$

\section{Methods and results}

\section{Development of the analytic framework}

In 2014, CL and JC were asked by the principal investigators to develop an analytic framework to guide the analysis of a case study of Indigenous health equity within ELPH Study 1. The World Health Organization (WHO) framework for social determinants of health ${ }^{28}$ and critical Indigenous theory ${ }^{29}$ informed development of this framework. Combining the concepts of proximal, intermediate and distal determinants with those related to colonial oppression, CL and JC attempted to shape a framework specifically focused on the relational, systemic and structural environments within which Indigenous public health is shaped. This framework is congruent with theoretical perspectives that inform the larger program of ELPH research, ${ }^{5}$ such as intersectionality, which focuses on diverse social locations, forces, and power structures that shape human life..$^{30,31}$

Alexandra Kent (AK) applied the framework to the data gathered from one of BC's health authorities. The details of the pilot case study, including the chosen health authority, have not yet been released to knowledge users or the public. The framework was later named Xpey' Relational Environments, after consultation with Shauna Underwood, an Indigenous Advisor at the University of Victoria. Xpey' means western red cedar in Hul'q'umi'num', a dialect within the Halkomelem language group spoken primarily by First Nations on Vancouver Island. There is no one word for tree in Hul'q'umi'num'; therefore, we chose western red cedar for its cultural significance as a sacred medicine.

Xpey' Relational Environments is adapted from a tree metaphor previously developed by CL to represent proximal, intermediate, and distal determinants of Indigenous health. ${ }^{15}$ The land-based metaphor uses biomimicry to provide a deeper analysis of abstract concepts through an understanding of the natural world. ${ }^{32}$ While not specific to Indigenous cultures, the tree metaphor offers an Indigenous cultural sensibility. CL explained the tree metaphor as follows:

We typically think of trees as possessing three interconnected elements: the crown (leaves and branches), the trunk, and the roots. Each part of the tree is dependent not only upon the other parts for sustenance and support, but also upon the environment that nourishes and sometimes damages them. ${ }^{33, \mathrm{p} .4}$

Whereas the health of the unseen roots strongly influences the health of the tree, the condition of the crown is often an indicator of the tree's overall health. Xpey' Relational Environments applies this understanding to the physical and theoretical settings, or 'relational environments', in which health equity is manifested in public health systems and structures.

Within Xpey', relational environments are conceptualized as the three elements of a tree: stem, core, and roots (Figure 1). Like the crown of a tree, stem environments influence individual and community health in the most obvious and direct ways, ${ }^{33}$

FIGURE 1

Visual representation of Xpey' Relational Environments framework

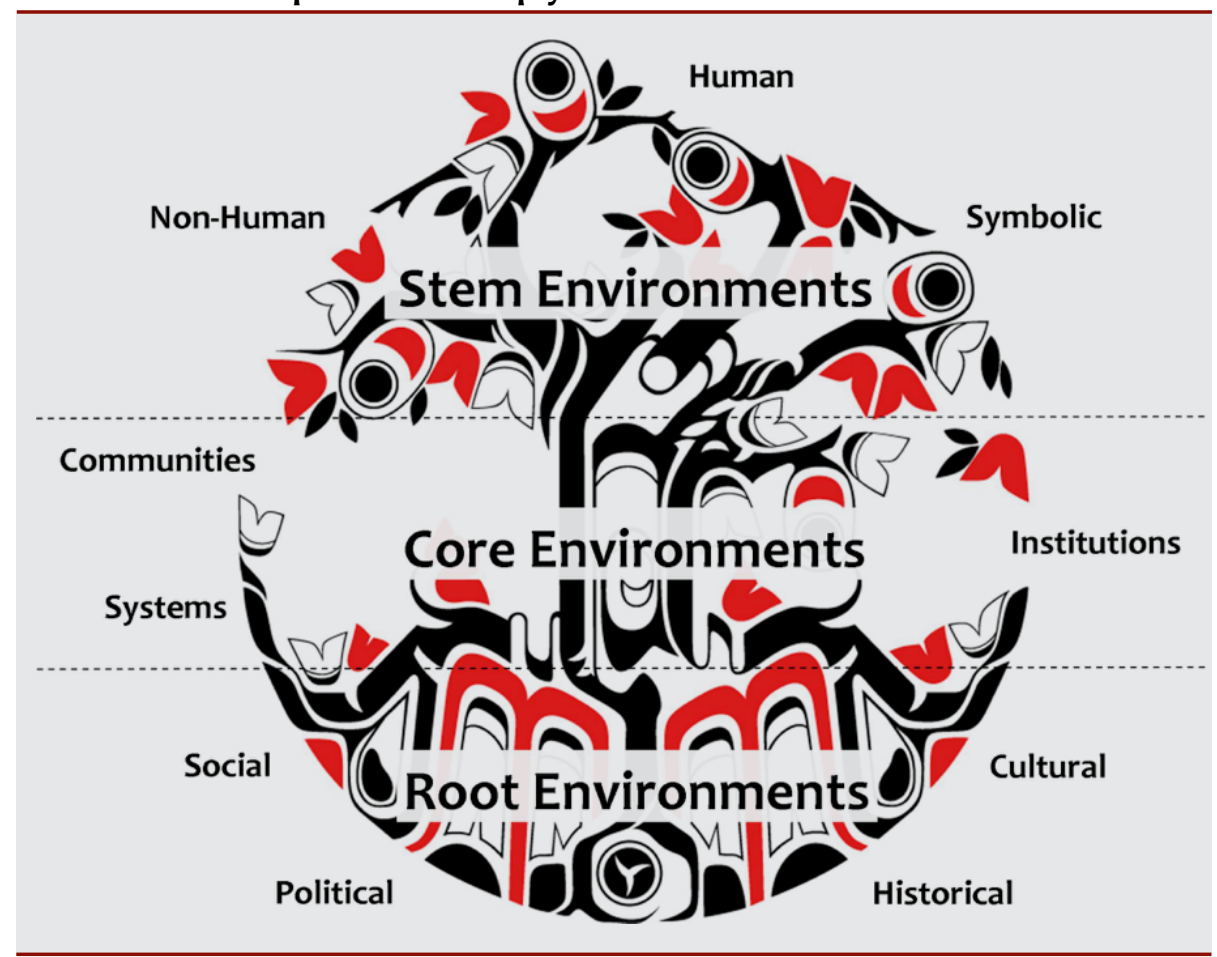

Source: Authors obtained permission from artist, kireihiryu, to use tree illustration. encompassing interpersonal relationships such as those between service providers and clients or patients; the natural and built environment, including barriers to services and resources; and the symbolic positioning or representation of people's intersectional identities and cultures.

Like the trunk of a tree, core environments connect stem and root environments in ways that can facilitate or hinder health. ${ }^{33}$ These relational environments have a less direct influence on the health of individuals, but they strongly influence the relationships and settings within the stem environment. Core environments include: systems of authorities, policies and bureaucracies; leadership and management within relevant institutions and organizations; and the local systems and structures at the community level.

Finally, root environments represent the historical, political, social and cultural contexts from which all other relational environments evolve. ${ }^{15}$ CL explained, "Just as maladies observed in the leaves are generally not the cause of unhealthy trees, inequities in human health frequently result from corruption or deficiencies in the unseen but critical root system"33,p.5. For Indigenous health and health governance, these roots take the 
form of colonial histories and intergenerational trauma, political relationships and arrangements, social and material inequities, and cultural connection or loss. Among these stem, core, and root relational environments, there are protective features that promote well-being and resilience, as well as risk factors that can produce unfavorable circumstances or hinder health.

\section{Application of the analytic framework}

Over the last four years, the ELPH team has undertaken a review of strategic plans, service plans, health equity plans, government reports, and other relevant documents in each of the health authorities. Document collection has occurred alongside in-depth interviews and focus groups with frontline staff, supervisors, managers and senior executives. Both sources of data were collected for baseline assessment in 2012/2013 and again for follow-up, which started in the summer of 2015 and came to a close in the spring of 2016.

All data from the pilot case study selected for analysis with the Xpey' Relational Environments framework were compiled and coded in NVivo10 qualitative software version 10 (QSR International Pty Ltd. 2012), a qualitative software package that helps store, organize, manage and analyze qualitative data. ${ }^{34}$ Initial codes were derived deductively, using Xpey’ Relational Environments for higher-level categorization into stem, core, and root environments. Inductive coding was also used to capture the depth and contextual detail of the content. NVivo supported the development of 'in vivo' code labels through use of word frequency queries to identify recurring terms and concepts in the sources. Data-driven codes serve as subcodes within the overarching theorydriven codes (stem, core and root environments). Once a point of saturation was reached, codes were refined and manually sorted by placing categories into relationship with others based on conceptual similarities until the best fit was achieved. As the code hierarchy was integrated into the theoretical framework, the relational environments came to life.

In 2015, CL secured a CIHR Planning and Dissemination Grant to hold a stakeholder engagement meeting with representatives from the BC public health system who are responsible for Indigenous health in their respective organizations. In early 2016, a one-day gathering of leaders from the Indigenous health departments of each of the organizations in BC's public health system was held, including the five regional health authorities, FNHA, the Provincial Health Services Authority, and the Ministry of Health. The majority of those in attendance were First Nations or Métis peoples who work closely with communities across the province. Preliminary findings from the pilot case study were presented to participants to solicit feedback on the Xpey' Relational Environments framework.

Several significant reflections and key recommendations came out of the stakeholder engagement meeting. Everyone in attendance agreed that Indigenous health equity is a critical issue in BC's public health system and that it should be a research priority. The stakeholders were also very supportive of Xpey' Relational Environments as a framework for analyzing Indigenous health equity. However, some participants expressed concern that ELPH was not originally conceived as an Indigenous health equity project, and they pointed out the limitations of adding an Indigenous focus through secondary analysis rather than situating the research in an Indigenous approach from the onset.

\section{Discussion}

ELPH is theoretically grounded in intersectionality $^{30,31}$ and social justice theory, ${ }^{18,35}$ as opposed to post-colonial, critical race theory or Indigenous world views, which is a significant and important limitation restricting use and application of the Xpey' Relational Environments framework within ELPH. ELPH is a collaborative research project with public health leaders within BC's health authorities (which began in 2011 before FNHA was formally introduced to BC's public health system and at a time when Indigenous departments had less presence within health authorities). ELPH research leads met with FNHA representatives once FNHA was established to invite them to be a partner. The research was already well in progress at the time, so we respected their decision not to partner and agreed to share updates and findings throughout the research process. Thus, data collected in ELPH does not reflect important work being done by and with Indigenous peoples within health authorities, in part, due to lack of partnerships and timing of the project. This creates a significant gap in the representation of Indigenous health equity work in BC's public health system.

The initial work and subsequent feedback generated during the stakeholder engagement meeting was invaluable and provided important guidance for the application of the Xpey' Relational Environment framework in future health equity research endeavours. Specifically, the use of the Xpey' Relational Environments framework as an analytic structure must be grounded within Indigenous research methodologies and led by Indigenous peoples. Furthermore, future applications of the framework-or adaptations of it-should include careful representation and consideration of the unique experiences of specific cultural groups (e.g. Métis). With further input into the framework from Indigenous Knowledge Holders and organizational leaders as well as the engagement of Indigenous-led research approaches, the Xpey’ Relational Environments framework could have utility in framing future research questions related to Indigenous equity in BC public health and elsewhere.

\section{Conclusion}

This application of Xpey' Relational Environments serves as an example of the analytic framework's utility for exploring and conceptualizing Indigenous health equity. The framework captures the critical importance of the determinants of Indigenous health equity in BC's formal public health system, but is also transferable to other studies and other contexts. One obvious application for future development is a focused analysis of FNHA's strategies to reduce inequities and enhance health equity for Indigenous peoples. Furthermore, Xpey' Relational Environments could be used as an analytic framework to explore local health systems within an Indigenous community context, using community-based participatory action research. Through our experience applying Xpey' Relational Environments to a pilot case study within the ELPH research program, we recognize that any future applications of this framework need to be situated within an Indigenous research process, informed by cultural protocols and guided by Elders or Knowledge Holders.

\section{Acknowledgements}

The authors disclosed receipt of the following financial support for the research, 
authorship, and/or publication of this article: Canadian Institutes of Health Research Operating Grant: Programmatic Grants to Tackle Health and Health Equity (CIHR, Grant 116688), and Canadian Institutes of Health Research Planning and Dissemination Grant: Institute Community Support (CIHR; Grant 345339).

\section{Conflicts of interest}

The authors declared no potential conflicts of interest with respect to the research, authorship, and/or publication of this article.

\section{Authors' contributions and statement}

BP and MM contributed to the study concept, research design and data collection. CL and JC provided methodological input and designed the analytic framework. AK piloted the framework, interpreted the findings and wrote the manuscript, with guidance from co-authors. All authors assisted in manuscript revision and approved the final version.

The views expressed in this article are the views of the authors and should not be taken to represent the views of the funders.

The content and views expressed in this article are those of the authors and do not necessarily reflect those of the Government of Canada.

\section{References}

1. Association of American Medical Colleges. The state of health equity research: closing knowledge gaps to address inequities [Internet]. 2014 [cited 13 Aug 2016]. Available from: https://members.aamc.org/eweb / upload/The $\% 20$ State $\% 20$ of $\% 20$ Health \% 20Equity \% 20Research \% 20 - \% 20Closing \% 20Knowledge \% 20 Gaps \% 20 to \% 20 Address $\% 20$ Inequities.pdf

2. Centre for Aboriginal Health Research. Linking GIHR and EMR: environmental scan and tool inventory [Internet]. 2010 [cited 18 May 2016]. Available from: https://www.uvic.ca/research /centres/circle/assets/docs/Publications /Enviro \% 20Scan \% 20Linking \% 20 GIHR \% 20and \%20EMR \%202.pdf
3. Rigney LI. Internationalization of an Indigenous anticolonial cultural critique of research methodologies: a guide to Indigenist research methodology and its principles. Wicazo Sa Review. 1999;14(2):109-21.

4. Iwama M, Marshall M, Marshall A, Bartlett $C$. Two-eyed seeing and the language of healing in community based research. Canadian Journal of Native Education. 2009;32(3):3-23.

5. Pauly BM, MacDonald M, Hancock T, Martin W, Perkin K. Reducing health inequities: the contribution of core public health services in BC. BMC Public Health. 2013;13(1): 550. doi: 10.1186/1471-2458-13-550.

6. Clarke AE. Situational Analysis: Grounded Theory after the Postmodern Turn. Thousand Oaks: Sage; 2005.

7. Borrows J. Wampum at Niagara: The Royal Proclamation, Canadian legal history, and self-government. In Asch M. (ed.) Aboriginal and treaty rights in Canada: Essays on law, equality, and respect. Vancouver: University of British Columbia Press; 1997. p. 155-72. Available from: http://www.sfu.ca / palys/Borrows-WampumAtNiagara .pdf

8. Canadian Coalition for Global Health Research, Centre for Aboriginal Health Research. Linking equity methods research and global Indigenous health research - Workshop [Internet]. 2010 [cited 7 May 2017]. Available from: http://www.cgh.uottawa.ca /assets/documents/news_2010_GIHR _equity_release.pdf

9. Whitehead M. The concepts and principles of equity and health. Health Promotion International. 1991;6(3): 217-28. doi: 10.1093/heapro/6.3.217.

10. Sparks M. A health promotion approach to addressing health equity. Global Health Promotion. 2010;17(1):77-82.

11. Adelson N. The embodiment of inequity: Health disparities in Aboriginal Canada. Can J Public Health. 2005; 96(S2):S45-S61.
12. British Columbia Office of the Provincial Health Officer. Highlights: pathways to health and healing: 2nd report on the health and well-being of Aboriginal people in British Columbia. Provincial Health Officer's Annual Report, 2007 [Internet]. 2007 [cited 13 Aug 2016]. Available from: http://www2.gov.bc.ca /assets/gov/government/ministries -organizations/ministries/health / aboriginal-health-directorate /abohlth11-var7.pdf

13. Butler-Jones D. Our population, our health and the distribution of our health. In The state of public health in Canada: Report of the Chief Public Health Officer [Internet]. Ottawa (ON): Public Health Agency of Canada; 2008 [cited 13 Aug 2016]. p. 19-33. Available from: http:// www.phac-aspc.gc.ca/cphorsphc -respcacsp/2008/fr-rc/cphorsphc -respcacsp06b-eng.php

14. Health Officers Council of British Columbia. Health inequities in British Columbia: A discussion paper. Public Health Association of British Columbia. 2008.

15. Reading C, Wien F. Health inequalities, social determinants and life course health issues among First Nations people in Canada [Internet]. National Collaborating Centre for Aboriginal Health. 2009 [cited 30 Nov 2016]. Available from: https://www.scribd. com / d ocument / 189362540 / Health-Inequalities-and-SocialDeterminants-of-Aboriginal-PeoplesHealth-Charlotte-Loppie-Reading-FredWien

16. Truth and Reconciliation Commission of Canada. Honouring the truth, reconciling for the future: summary of the final report of the Truth and Reconciliation Commission of Canada [Internet]. Winnipeg, MB: Truth and Reconciliation Commission of Canada. 2015 [cited 11 May 2017]. Available from: http://www .trc.ca/websites/trcinstitution/index .php?p $=890$

17. Ministry of Health. Promote, protect, prevent: our health begins here. BC's guiding framework for public health. Province of British Columbia; 2013.

18. Powers M, Faden R. Social Justice: The Moral Foundations of Public Health and Health Policy. New York: Oxford University Press; 2006. 
19. Aboriginal Affairs and Northern Development Canada. Highlights from the report of the royal commission on Aboriginal people [Internet]. Government of Canada; 1996 [cited 13 Aug 2016]. Available from: http://www .aadnc-aandc.gc.ca/eng/1100100014597 /1100100014637

20. Lavoie J, Gervais L, Toner J, Bergeron O, Thomas G. Looking for Aboriginal health in legislation and policies, 1970 to 2008: the policy synthesis project final report. National Collaborating Centre for Aboriginal Health. 2011. Available from: https://www .researchgate.net/publication /273729711_Looking_for_Aboriginal _Health_in_Legislation_and _Policies_1970_to_2008_The_Policy _Synthesis_Project

21. Kelly MD. Toward a new era of policy: health care service delivery to First Nations. International Indigenous Policy Journal. 2011;2(1): 1-12.

22. First Nations Health Council. Implementing the vision: BC First Nations health governance: Reimagining First Nations health in BC. First Nations Health Council. 2011.

23. Hirch M. Self-determination in Indigenous health: a comprehensive perspective. Fourth World Journal. 2011;10(2):1-30.

24. Webster P. Local control over Aboriginal health care improves outcome, study indicates. Canadian Medical Association Journal. 2009; 181(11):249-250. doi: 10.1503/cmaj .109-3072.

25. Population Health and Wellness, Ministry of Health Services. A framework for core functions in public health - resource document [Internet]. Province of British Columbia. 2005 [cited 13 Aug 2016]. Available from: http://www.health.gov.bc.ca/library /publications/year/2005/core_ functions.pdf

26. Province of British Columbia. About public health [Internet]. [cited 13 Aug 2016]. Available from: http://www2 .gov.bc.ca/gov/content/health/about -bc-s-health-care-system/

27. Government of Canada. British Columbia Tripartite Framework Agreement on First Nations Health Governance. Aboriginal Affairs and Northern Development Canada; 2011.
28. World Health Organization Commission on Social Determinants of Health. A conceptual framework for analysis and action on the social determinants of health [Internet]. Geneva: WHO; 2010 [cited 7 May 2017]. Available from: http://www.who.int/sdhconference /resources/onceptualframeworkfor actiononSDH_eng.pdf

29. Moreton-Robinson A. Introduction: critical Indigenous theory. Cultural Studies Review, 2009;15(2):10-2. doi: 10.5130/csr.v15i2.2034.

30. Hankivsky O, Cormier R. Intersectionality: moving women's health research and policy forward. Women's Health Research Network. Vancouver. 2009.

31. Walby S. Theorizing multiple social systems. In Globalization and inequalities: complexity and contested modernities. London: Sage. 2009. p. 58-100.

32. Wahl DC. Learning from nature and designing as nature: regenerative cultures create conditions conducive to life. [Web Log Post] The Biomimicry Institute [Internet]. 6th September 2016 [cited 27 Sept 2017]. Available from: https://biomimicry.org/learning -nature-designing-nature-regenerative -cultures-create-conditions-conducive -life/

33. Reading C. Structural determinants of Aboriginal peoples' health. In Greenwood M, de Leeuw S, Lindsay NM, Reading C (eds.) Determinants of Indigenous peoples' health in Canada: beyond the social. Toronto, ON: Canadian Scholars' Press; 2015. p. 3-15.

34. QSR International. About NVivo [Internet]. Technical resource center. [cited 13 Aug 2016]. Available from: http://techcenter.qsrinternational. com/desktop/nv10/nv10_about_ nvivo_htm

35. Fraser N. Re-framing justice in a globalizing world. In Fraser N, Bourdieu P, Lovel $\mathrm{T}$ (eds.) (Mis)recognition, social inequality and social justice. New York: Routledge; 2007. p. 17-35. 